\title{
JUVENTUd RURAL, GÉNERO Y MÚSICA: El CASO DE LA FILARMÓNICA JUVENIL San Martín Tilcajete, OAXaca, México
}

\author{
Rural Youth, Gender and Music: The Case of the \\ San Martín Tilcajete Youth Philharmonic, Oaxaca, Mexico
}

\author{
Jonathan Ojeda-Gutiérrez* \\ Pilar Alberti-Manzanares** \\ Emma Zapata-Martelo***
}

DOI: http://dx.doi.org/10.29043/liminar.v19il.796

\begin{abstract}
Resumen: El objetivo de este artículo es reflexionar sobre la influencia de la educación musical en mujeres jóvenes rurales, con base en sus experiencias como músicas en la Filarmónica Juvenil San Martín Tilcajete. Se hizo uso de la metodología cualitativa desde la perspectiva de género y se realizaron entrevistas a profundidad e historias de vida. Los resultados muestran que la filarmónica fue un proyecto que buscó potencializar la agencia de las jóvenes como sujetos políticos, promoviendo su autonomía a través de la educación musical. Esta iniciativa intentó influir en los procesos de empoderamiento de las jóvenes; sin embargo, se presentaron factores impulsores como el apoyo familiar, e inhibidores relacionados con estereotipos tradicionales de género. Esto se tradujo en conflictos, compensaciones y negociaciones, eventos por los que atraviesan las mujeres para alcanzar su autonomía.
\end{abstract}

Palabras clave: juventud rural, género, educación musical, empoderamiento.

Abstract: This article explores the influence of music education in rural young women, based on their experiences as musicians in the San Martín Tilcajete Youth Philharmonic. A qualitative, gender-perspective methodology was used and in-depth interviews and life stories were conducted. The results show that the philharmonic was a project that sought to empower the agency of young women as political subjects, promoting their autonomy through music education. This initiative attempted to influence the empowerment processes of young women; however, there were driving factors such as family support and inhibitors related to traditional gender stereotypes. This led to conflicts, compensation, and negotiations, events that women go through to achieve their autonomy.

Keywords: rural youth, gender, musical education, empowerment.

\footnotetext{
* Jonathan Ojeda Gutiérrez. Maestro en Ciencias en Desarrollo Rural por el Colegio de Postgraduados en Ciencia Agrícolas, México. Estudiante del Doctorado en Ciencias en Ciencias Agrarias, Universidad Autónoma Chapingo, México. Temas de especialización: género, masculinidades y juventudes. Correo electrónico: nunatak_82@hotmail. com. ORCID: https://orcid.org/0000-0002-1110-1160

** Pilar Alberti Manzanares. Doctora en Antropología y Etnología de América por la Universidad Complutense de Madrid, España. Profesora-investigadora titular del Colegio de Postgraduados en Ciencias Agrícolas, Área de Género: Mujer Rural, Campus Texcoco, México. Temas de especialización: antropología, desarrollo rural y gé-
}

nero. Correo electrónico: palberti@colpos.mx. ORCID: https://orcid. org/0000-0003-0031-8986

*** Emma Zapata Martelo. Doctora en Sociología por la University of Texas, in Austin, Estados Unidos. Profesora-investigadora titular del Colegio de Postgraduados en Ciencias Agrícolas, Área de Género: Mujer Rural, Campus Texcoco, México. Temas de especialización: sociología, desarrollo rural y género. Correo electrónico: emzapata@colpos. mx. ORCID: https://orcid.org/0000-0002-1623-3322

Enviado a dictamen: 30 de enero de 2020. Aprobación: 25 de agosto de 2020. 


\section{Introducción}

$\square$ ste artículo forma parte de los resultados de la investigación de tesis de maestría en Estudios del Desarrollo Rural sobre música, género e identidades juveniles, la cual se realizó en el municipio de San Martín Tilcajete, Oaxaca. ${ }^{1}$ El objetivo es mostrar cómo influyó a nivel personal y subjetivo la educación musical en las mujeres jóvenes que participaron en la Filarmónica Juvenil San Martín Tilcajete, que estuvo activa de 2004 a 2010. Se consideró identificar los obstáculos que enfrentaron para integrarse al proyecto y durante su participación debido a los estereotipos hegemónicos y reduccionistas de género que imperan en la comunidad y en la docencia musical.

Para cumplir con el objetivo se hizo una revisión teórica para problematizar la noción de juventud considerando las categorías de género, etnia y clase, así como las actividades lúdicas y los espacios de socialización. Lo anterior se realizó para señalar que la juventud es un sujeto situado que vive en un contexto, en un tiempo específico y en relaciones complejas. Esto posibilita dejar atrás la mirada ingenua y homogénea sobre las juventudes rurales (Bevilaqua, 2009; Buendía, 2013; De Garay, 2000; Duarte, 2001; Margulis y Urresti, 2002). La metodología empleada fue cualitativa, se realizaron entrevistas a profundidad e historias de vida orientadas a los temas de género y educación musical. ${ }^{2}$ El análisis de la información se realizó desde el enfoque de género para discutir las desigualdades estructurales entre sexos que afectan a las jóvenes rurales (Duarte, 2001).

Los hallazgos de la investigación arrojan que la educación musical influye en los procesos de empoderamiento de las jóvenes, pues más allá de potencializar la capacidad psicomotriz y el desarrollo intelectual y promover el establecimiento de relaciones sociales, logra incidir en la capacidad de agencia que tiene el sujeto para actuar en el mundo. El empoderamiento tiene esa finalidad, superar y transformar imaginarios sociales sobre la feminidad y las relaciones de poder entre géneros (Santana, Kauffer y Zapata, 2006). Sin embargo, estos procesos son complejos porque se pre- sentan conflictos, compensaciones y negociaciones, e intervienen factores como la edad, la etnia, la clase, el contexto y las condiciones de vida (Hidalgo, 2002). Por último, esta investigación busca contribuir a ampliar el horizonte epistémico sobre el estudio de las juventudes rurales desde el enfoque de género, para lo cual se señala que es pertinente considerar a este grupo social como sujetos situados, cuyas prácticas sociales y cotidianas tienen un valor cualitativo para comprender y transformar el mundo,

\section{Interconexiones: juventud rural, género y educación musical}

\section{Un acercamiento al concepto de juventud}

La juventud se ha considerado como un periodo de transición biológica y psicológica de la niñez a la adultez, etapa de aprendizaje para que el sujeto logre insertarse en el mundo adulto con independencia económica y con la posibilidad de formar una familia, entre otras características propias de la modernidad capitalista (Paz, Suárez y Espinosa, 2018). Este proceso no es lineal, sino complejo, debido a que existen categorías como clase, etnia y género que son un punto de inflexión para repensar la configuración de las identidades juveniles.

Para Reguillo (2007), la juventud es una categoría que forma parte del sistema de clasificación social; este está conformado por identidades socialmente construidas, cambiantes en sus contenidos y sus representaciones. Son otras formas de estar en el mundo, lo que para Zemelman sería "la necesidad del sujeto de ser sujeto según los sentidos que lo impulsan a pensar y actuar" (2012:21). Sin embargo, sus representaciones y sus formas de inserción en la estructura social son diferenciadas y desiguales.

Existe una multiplicidad diacrónica y sincrónica en los modos de "ser joven", pues "las formas como se constituye la juventud varían en cada sociedad [...] las cuales son cambiantes, se construyen y reconstruyen en la interacción social y en contextos específicos" (De Garay, 2000:111). Por ello, no hay "juventud" sino juventudes. Su caracterización depende de distintas variables 
como la diferenciación social, el género, la generación y el entorno social (Margulis, 2001; Margulis y Urresti, 2002). En este sentido, la juventud rural aparece dentro del sistema de clasificación social de las identidades juveniles, en el que intervienen la etnia y otras particularidades socioculturales.

\section{Juventud rural: una invención de la sociedad industrial}

La categoría "juventud rural" es una invención de la sociedad industrial cuyo constructo se inició en las últimas décadas del siglo XIX y se consolidó en el siglo XX (Bevilaqua, 2009). La modernización del campo y de la agricultura no solo involucraba el uso de tecnologías para la explotación de la tierra, sino la invención de un nuevo sujeto al servicio del capital. Para lograrlo se planteó integrar a la juventud rural a instituciones de educación encaminadas al desarrollo, con la finalidad de producir sujetos "modernos", "disciplinados" y "trabajadores"; se consideraba erróneamente que lo rural era lo atrasado y lo urbano lo moderno.

Sin embargo, este reduccionismo omitía problemáticas relacionadas con "las redes de relaciones económicas, políticas y culturales en que la juventud y sus familias están inmersas" (Bevilaqua, 2009:621), como la tenencia de la tierra, los sistemas productivos, la posición social, la pertenencia a una etnia y las desigualdades de género. Para Sili, Fachelli y Meiller (2016), las reflexiones sobre juventud rural deben considerar el género como categoría de análisis, pues "el grado de marginación es más profundo cuando la edad se cruza con el género" (Buendía, 2013:14). Esto permite tener una mirada menos ingenua de la juventud rural, porque categorías como el género muestran y evidencian problemáticas como las desigualdades sociales por razones de sexo. En este sentido, coincidimos con Urteaga (2019) cuando señala que es necesario orientar los estudios sobre juventudes desde sus propios contextos como sujetos situados en circunstancias complejas y heterogéneas. Esto exige un cambio teórico del "deber ser joven" constituido en el siglo XXI, para ampliar el horizonte epistémico sobre el estudio las juventudes contemporáneas.

\section{Género: un enfoque para los estudios sobre juventudes rurales}

El enfoque de género en los estudios sobre juventud permite "instalar en la reflexión otros elementos no considerados hasta ahora para mirar, aprehender y comprender a las juventudes en nuestras sociedades" (Duarte, 200l:68). Alberti (2011) considera que el género es una categoría teórico-metodológica que analiza la construcción sociocultural de las diferencias entre mujeres y varones, a la vez que critica las relaciones de poder y de dominación por razones de sexo. Su crítica a la construcción social del género considera los factores culturales, psicológicos, etarios, económicos, sociales y políticos. Advierte, asimismo, que las relaciones de dominación deben cambiarse si se anhela una sociedad en la que imperen la justicia, la igualdad y la equidad. Para Lorey (2017), dicho enfoque posibilita identificar la capacidad de agencia del sujeto para resignificar los significados establecidos.

El enfoque de género llevado al estudio de las juventudes permite analizar cómo se constituyen las subjetividades e identidades femeninas y masculinas juveniles. Ello identificando que son sujetos situados que en sus experiencias y prácticas cotidianas encuentran el campo idóneo para conocer y comprender qué tan receptivas(os) son ante las propuestas de reivindicación de los derechos de las mujeres. Para el Colectivo Hombres y Masculinidades, la juventud es "una población que manifiesta formas de masculinidad y feminidad emergentes que son importantes reconocer a la hora de adelantar acciones de transformación" (2009:46). Esto implica tomar en cuenta las experiencias sobre sus vivencias relacionadas con el género, sin dejar de lado: 1) la posición del sujeto, las formas en que se relaciona con el mundo; 2) las configuraciones críticas, la juventud como una construcción compleja en la que existen momentos críticos que afectan su capacidad de agenciamiento, y, por último, 3) la dimensión narrativa de las carreras personales, que es donde "se sitúa el proceso constituyente del sí mismo, a la manera de proyectos de identidad" (García y Serrano, 2004:67). Para Urteaga (2019), la experiencia del sujeto joven está situada en 
un contexto y relacionada con narrativas colectivas en las que reinscriben su "yo joven".

Esta reinscripción del "yo joven" tiene conexión con la agencia de la juventud como "actores sociales capaces de producir cultura juvenil, en los espacios de sociabilidad creados en la convivencia en las instituciones, en sus poblados de origen, en los tiempos de ocio o en las situaciones lúdicas y festivas" (Bevilaqua, 2009:651). Uno de esos espacios de sociabilidad está vinculado a la música, expresión cultural que tiene un carácter social que promueve la colectividad humana, en este caso la comunidad entre jóvenes.

Orquestas juveniles: educación musical para la inclusión social

El filósofo griego Aristóteles (2005) señalaba que la educación musical contribuye a la formación del carácter de la juventud, pues potencializa el desarrollo de su sensibilidad, sus emociones, y tiene un valor formativo. La música y su enseñanza tiene una función social que opera a nivel personal, colectivo y subjetivo en tres dimensiones: la fisiológica — capacidad psicomotriz-, la psicológica —desarrollo intelectual-y la sociológica —establecimiento de relaciones sociales- (De la Ossa, 2011; Hormigos, 2012; Reynoso, 2010). En este orden de ideas, las orquestas juveniles como modelo de inclusión y desarrollo se gestaron bajo estos criterios. En América Latina tienen su génesis en el modelo "Sistema de Orquestas Juveniles e Infantiles de Venezuela", fundado por el maestro José Antonio Abreu en 1975 (Wald, 2017).

Este modelo se ha extendido a más de cincuenta países, incluido México, y su finalidad es el rescate de la infancia y la juventud a través de la integración cultural. El objetivo es utilizar la educación musical como instrumento para promover la inclusión social de la juventud que habita en zonas populares y marginadas; destaca el hecho de que la vida de gran parte de las juventudes latinoamericanas se sitúa en contextos de precariedad y vulnerabilidad resultado de una sociedad marcada por la desigualdad que trae como consecuencia la fragmentación social. ${ }^{3}$ De esta manera, las orquestas emergen como una alternativa que le posibilita al sujeto joven un proyecto biográfico diferente.
En México, el promotor del movimiento de orquestas infantiles y juveniles fue Eduardo Mata, director de orquesta y compositor. Su objetivo era conformarlas bajo los referentes culturales de cada región para despertar el interés por la música tradicional mexicana, así como su preservación (Hernández, 2014). Sin embargo, la educación musical en zonas rurales es desatendida de manera sistemática por gobiernos locales y federales (Flores, 2011). Son las propias comunidades las promotoras y responsables de crear estrategias de enseñanza y aprendizaje para el desarrollo comunitario Un ejemplo exitoso de ello es el Centro de Capacitación Musical Mixe (CECAM), ubicado en la comunidad de Santa María Tlahuitoltepec, Oaxaca. Inició en 1977 como un programa social, impulsado por el Fondo Nacional para las Actividades Sociales (FONAPAS) y el Instituto Nacional Indigenista (INI). Actualmente funciona como asociación civil.

ElCECAM tiene como objetivo educar y formar músicos con principios comunitarios, así como fomentar y fortalecer valores culturales e identidad histórica de la región mixe (Esparza, 2016). Los proyectos de este tipo tienen una función identitaria porque a través de la música se da una transmisión cultural, relacionada con "prácticas sociales y manifestaciones culturales donde convergen cosmovisiones, valores y epistemologías locales" (Vargas, 2016:82). La música y su enseñanza son un lugar social que impulsa al sujeto joven a construir lazos de interrelación y afecto. Estos proyectos no solo funcionan como estrategia para promover la inclusión social de la juventud, sino que además aportan elementos para el desarrollo rural.

En este orden de ideas, reflexionar sobre las juventudes rurales exige aceptar que su construcción identitaria es un proceso siempre dinámico. De acuerdo con Urteaga (2019), la juventud se constituye a partir de múltiples factores como el género, la clase, la etnia, la política, la nacionalidad, los gustos musicales, etcétera. A través de estos factores la juventud construye la realidad, y estos factores a su vez construyen a las juventudes. Por eso es pertinente hablar de juventudes y problematizarlas desde sus propios contextos, espacios de sociabilidad y situaciones lúdicas y festivas. 


\section{Aspectos metodológicos}

La metodología empleada fue cualitativa para el abordaje de las realidades subjetivas e intersubjetivas de los sujetos de estudio, bajo la consideración de que la vida social es digna de ser estudiada pues en ella el objeto de conocimiento son sujetos que se mueven, incluido el investigador o investigadora (Sandoval, 2002; Taylor y Bogdan, 1994). Para recabar la información se realizaron entrevistas a profundidad y se recopilaron historias de vida relacionadas con los temas de juventud, género y educación musical a fin de identificar tanto la influencia que tuvo la educación musical a nivel personal y subjetivo, como los obstáculos socioculturales que las jóvenes enfrentaron. Para tal efecto se partió de la experiencia de mujeres jóvenes que participaron en la filarmónica.

El análisis de la información se hizo desde el enfoque de género, aporte metodológico para el análisis de la vida personal y colectiva, así como una opción política para mejorar las sociedades y fomentar la equidad (Rosas y Zapata, 2007). Desde este enfoque se conoce que la construcción social del género es relacional; sin embargo, para los fines de este documento se hace énfasis principalmente en los testimonios de las jóvenes para cumplir con los objetivos planteados.

La finalidad de elegir la Filarmónica Juvenil de San Martin Tilcajete consistió en documentar la relevancia e influencia que tuvo esta iniciativa a nivel individual y colectivo debido a que se identificó una relación entre las prácticas culturales - vinculadas con la asistencia a la orquesta- con la construcción de las relaciones de género en la comunidad. La perspectiva de género ayudó a identificar las desigualdades sociales que enfrentaron las jóvenes al participar en el proyecto, pues uno de los objetivos de este fue potenciar la agencia de las mujeres a través de la educación musical.

El estudio se llevó a cabo entre enero y julio de 2016, en el poblado de San Martín Tilcajete, comunidad de origen zapoteca perteneciente al distrito de Ocotlán, de la región de Valles Centrales, en el estado Oaxaca. El poblado se rige bajo el sistema de usos y costumbres, organización política municipal usual en el estado. La comunidad tiene como principales actividades econó- micas las siguientes: la migración internacional, con el envío de remesas, que ocasiona cambios en las estructuras familiar y demográfica; la elaboración y producción de artesanías en madera conocidas como "alebrijes", y el turismo (Jiménez y Serrano, 2014).

La unidad de análisis fue la Filarmónica Juvenil de San Martin Tilcajete, que estuvo activa de 2004 a 2010. De acuerdo con la información recabada, esta filarmónica se creó con los siguientes objetivos: 1) desarrollar capacidades, habilidades y cualidades musicales, que favorecieran al desarrollo integral de las/os jóvenes de la comunidad; 2) incorporar a niñas y mujeres jóvenes en la educación musical, destacando que tienen las mismas capacidades y cualidades que los varones, y 3 ) disminuir la migración de jóvenes a través de la educación musical como una potencial fuente de ingresos económicos ante la falta de oportunidades laborales en la región.

Se realizaron trece entrevistas para conocer: el origen de la filarmónica, los beneficios de la educación musical a nivel personal, las dificultades en los procesos de aprendizaje y enseñanza musical por motivos de género, el apoyo de familiares e instituciones a las y los jóvenes músicos, y las experiencias de vida sobre presentaciones. Las entrevistas se realizaron a siete mujeres y varones jóvenes, de 16 a 24 años de edad, que participaron en la filarmónica, un profesor de música de la Misión Cultural, un profesor de educación artística de la Escuela Secundaria Técnica 130, un regidor de Educación del ayuntamiento municipal y dos fundadores de la Filarmónica Juvenil San Martín Tilcajete.

\section{Resultados}

\section{La génesis y desintegración de la filarmónica}

La música es una expresión estética que se encuentra presente en la vida cotidiana del sujeto, tiene una función estimulante en la sociedad, y promueve relaciones humanas y la transformación social (Hormigos, 2012). Estos preceptos fueron los que impulsaron a un matrimonio joven de la comunidad a formar el proyecto de la filarmónica. El objetivo era potenciar las virtudes de la niñez y de la juventud a través de la educación 
musical, idea que surgió de la experiencia del fundador, quien en su juventud vio limitado su acceso a la educación y al trabajo por la precariedad laboral, por lo que decidió emigrar a Estados Unidos en la década de los noventa del siglo pasado para acceder a una mejor calidad de vida.

El fundador señalaba que "Tilcajete se ha caracterizado por ser una comunidad de emigrantes, principalmente a Estados Unidos". Como ejemplo, el fenómeno migratorio en Oaxaca tuvo un saldo neto de 527272 personas que, ante la falta de empleo, salieron del estado entre 1990 y 2000, por lo que la población en los municipios disminuyó considerablemente (Alvarado, 2008). Para 2014, la Dirección General de Población de Oaxaca posicionó al estado en el lugar 11 a nivel nacional en cuanto al rubro de entidades federativas de procedencia de los migrantes a Estados Unidos, siendo California el principal estado de residencia (DIGEPO, s/f).

La experiencia del fundador como migrante motivó que a su regreso a México, y después de establecerse en Oaxaca con un trabajo, decidiera emprender el proyecto en compañía de su esposa y con recursos propios. Posteriormente los padres y madres de familia apoyaron económicamente para cubrir los sueldos del profesorado de música. Al no ser una iniciativa comunitaria, no fue aprobada por ninguna asamblea:

[...] nosotros pusimos la casa, pusimos sillas, colocamos un pizarrón pautado, pagamos el sueldo de los maestros de música porque no era sencillo traerlos, nos encargamos de la selección de alumnas y alumnos [...], los padres de familia después apoyaron con el pago de los profesores de música (entrevista al fundador, 2016).

La iniciativa del proyecto partía de hacer frente al rezago educativo y a la desigualdad social que se vive en el estado de Oaxaca. De acuerdo con el Consejo Nacional de Evaluación de la Política de Desarrollo Social (CONEVAL, 2018), Oaxaca es una de las entidades que presenta mayor porcentaje (29\%) de rezago educativo, por arriba del promedio nacional. El proyecto de la filarmónica pretendía hacer frente a este problema a través del arte para contribuir a la transformación social de la comunidad.

Las jóvenes se integraron al proyecto por invitación de los fundadores, quienes acudieron al domicilio de ellas para solicitar permiso a los padres de familia. Es necesario aclarar que ninguna de las jóvenes tenía formación musical previa y que adquirieron los conocimientos en el proyecto. El repertorio que elaboró la filarmónica estaba integrado principalmente por música tradicional oaxaqueña.

Otro objetivo del proyecto fue promover la equidad de género a través de la educación musical: "la idea era rescatar al sexo femenino, porque en Oaxaca se piensa que las mujeres sirven solo para la cama y la cocina para nosotros tienen las mismas cualidades que el hombre" (entrevista al fundador, 2016). En cuanto al contexto, en Oaxaca, durante el primer cuatrimestre de 2019 se incrementó en un $33 \%$ el homicidio de mujeres por razones de género (Sosa, 2019), y la violencia de género en la entidad se presenta como una problemática en la que intervienen elementos socioculturales —etnia, clase y edad, entre otrosque limitan el desarrollo de las mujeres y promueven la desigualdad, lo cual desencadena una serie de manifestaciones violentas contra ellas.

En Tilcajete, de acuerdo con Jiménez y Serrano (2014), impera una "cultura machista" que está arraigada en la conciencia colectiva de mujeres y hombres, según la cual se conciben los roles femeninos y masculinos de manera jerarquizada, lo que agudiza las diferencias de género. Estas diferencias están presentes en los discursos, en las prácticas cotidianas, en los lazos afectivos, en las relaciones interpersonales y en la división sexual del trabajo para justificar el trabajo reproductivo como una actividad exclusiva de las mujeres. Esto impacta en la cosificación de las mujeres y en la desvalorización de sus capacidades, lo que las hace aparecer como sujetos disciplinados y subordinados a los intereses de los hombres. En este sentido, el proyecto se planteó incluir a las niñas y a las mujeres jóvenes para reorientar este discurso e impulsar cambios que beneficiaran a nivel individual y colectivo, potenciando sus capacidades y virtudes, es decir, su agencia como sujetos. 
Ya conformada la filarmónica, llegaron a ofrecer conciertos en el interior de la República Mexicana y en Kansas City (Estados Unidos). Por ejemplo, en su viaje al extranjero: "se hizo un concierto en una escuela, ahí se quedaron muy sorprendidos del músico oaxaqueño, de su talento y habilidad para tocar sus instrumentos, ahí fue donde las niñas y niños recibieron invitaciones para estudiar música en Estados Unidos" (entrevista al fundador, 2016). Sin embargo, esto último no se logró por la falta de recursos económicos, ya que los padres y madres tendrían que cubrir los gastos de alimentación y hospedaje durante el tiempo de la estancia.

A pesar de los logros, el proyecto finalizó después de seis años; en 2010 dieron su último concierto. Los motivos de la suspensión estaban relacionados con la falta de apoyo económico por parte de las autoridades e instituciones gubernamentales encargadas de la promoción y difusión cultural, además de con la desconfianza de algunos padres de familia sobre la administración de la Filarmónica Juvenil San Martín Tilcajete:

Se pensaba que teníamos ganancias cuando no era así, siempre la prioridad era la filarmónica [...], después del viaje a Estados Unidos, algunos de los padres de familia decían que hubo más [ganancias] para alguien, para nosotros no hubo ganancias, pero contentos por lo que logramos, a partir de eso se rompe el proyecto (entrevista a fundadora, 2016).

Al producirse la ruptura, los padres de familia organizaron una asamblea para crear un comité y dar continuidad al proyecto; fue así como "se organizaron para ir al municipio y pedir apoyo, lo obtienen y crean la banda infantil, pero ya era de la casa del pueblo y ya no tenía nada que ver con la de nosotros" (entrevista a fundador, 2016). Esto logró la apertura de la Casa de Cultura, donde actualmente la Misión Cultural imparte clases de música a niñas, niños y jóvenes.

\section{Obstáculos en el camino: estereotipos sociales de género}

En las sociedades modernas imperan modelos culturales patriarcales que definen la posición del sujeto sobre lo femenino y lo masculino. Esto regula las relaciones sociales de género y crea así un sistema caracterizado por una profunda desigualdad social que coloca a las mujeres en desventaja frente a los varones. En este orden de ideas, la imagen femenina en Tilcajete está constituida bajo este discurso de inferioridad y de vulnerabilidad (Jiménez y Serrano, 2014). Lo anterior no permitió que fuera sencilla la incorporación de las niñas y las jóvenes al proyecto. El fundador argumentó: "me molestaba que los padres dijeran: 'no, te mando a mi hijo, pero a mi hija no' y pues no llegaban”. Esto muestra que el sujeto masculino es educado y estimulado para apropiarse de los espacios, ya sean públicos o privados. Existe una permisibilidad que se extiende hasta su vida adulta. Sin embargo, las niñas y jóvenes se fueron integrando: "Las mamás lo pensaron mucho, en ocasiones iban por ellas al lugar de ensayo, decían: 'cómo van a andar las mujercitas tan noche'. Para las salidas a conciertos era lo mismo: 'iquién las va a cuidar?' Nos organizamos y se formó un comité que atendiera eso" (entrevista a fundadora, 2016)

El testimonio anterior es un ejemplo de lo que señala Butler (2017), que declarar a las mujeres como vulnerables es resultado de la distribución desigual del poder y funciona como una forma de definir los géneros. Las dificultades que enfrentaron las niñas al considerarlas vulnerables se relacionan con una violencia simbólica, la cual "puede tomar formas muy diversas e incluso extraordinariamente refinadas [...] que tiene siempre como efecto la desvalorización" (Bourdieu y Passeron, 1996:9). Es decir, lo simbólico como forma de poder androcéntrico se ejerce directamente sobre el cuerpo de las mujeres (sumisión femenina) como mecanismo de control social.

Para los fundadores, declarar a las mujeres como vulnerables estaba relacionado con las costumbres de la comunidad, en el marco de las cuales la imagen femenina está vinculada con las tareas del cuidado y como prestadoras de servicios afectivos y sexuales (Burin, 2012). Lo anterior se debe, pues, a que "en el pueblo se siguen criando y educando a las mujeres para ser sumisas y no levanten la voz, eso se les hace normal" (entrevista a Griselda, 22 años, 2016). Puede advertirse que los roles 
de género están justificados por los procesos de crianza según los cuales las mujeres deben ser serviciales — ser seres para otros-, lo que sostiene y romantiza la división sexual del trabajo.

Sin embargo, para una de las informantes esto ha cambiado un poco porque ella puede asistir a la escuela, a diferencia de su mamá que no pudo hacerlo. Pero advierte que aún predominan diferencias entre mujeres y varones. Por ejemplo:

[...] mi hermano se iba a tocar y llegaba a la hora que quisiera. Si yo decía: "me invitaron a tocar, ipuedo ir?". "No, porque no sabes cómo te vas a regresar". Se ve una diferencia. Decían: "icómo vas a andar en la calle sola?". Mi hermano se iba solo, y yo, pues, no podía salir sola, o sea que sí se ve la diferencia (entrevista a Norma, 17 años, 2016).

Los constructos socioculturales de género en Tilcajete responden a todo un entramado simbólico y a expresiones materiales que se dan en el territorio que habita el sujeto, espacio donde se proyectan sus concepciones sobre el mundo. Este complejo sociocultural denominado como sistema de "usos y costumbres" es "un conjunto de formas y procedimientos de organización política, social y cultural que pueblos indígenas han venido manteniendo, desarrollando y transformando a lo largo de su historia" (Bailón, Sorroza y Eisenstadt, 2016:27). Este funciona para normar la vida en comunidad, le da sentido de pertenencia al sujeto e interviene en la constitución de identidades femeninas y masculinas.

En opinión de Vázquez, Cárcamo y Hernández (2011), los "usos y costumbres" como régimen normativo colectivo no solo regulan la vida comunitaria, sino también el comportamiento "adecuado" de mujeres. Por ejemplo: "[...] en una comunidad rural como Tilcajete, cuando te casas, el hombre es quien te mantiene [proveedor], y como mujer te dedicas a los quehaceres domésticos y a la educación de los hijos, nada más" (entrevista a Griselda, 22 años, 2016).

De acuerdo con Jiménez y Serrano (2014), en Tilcajete, cuando una mujer se casa, se le aísla de su familia de origen y de sus redes de apoyo ya que ha formado una nueva familia. Para Vázquez y Muñoz (2013), es importante prestar atención a las desigualdades que pueden manifestarse en este complejo sociocultural que relega a las mujeres a actividades "propias de su sexo", porque esto complica los procesos de empoderamiento y las excluye de la toma de decisiones.

Sin embargo, los "usos y costumbres" son parte de los procesos de constitución identitaria de los sujetos:

[...] debido a que una colectividad que no pueda decidir sobre su modo de vida, que no pueda vivir según los valores que considera fundamentales, que no pueda organizar su vida colectiva de acuerdo a sus propias normas, es una colectividad desprovista de identidad. Es, con otros términos, una colectividad moribunda (Giménez, 2016:139).

En este sentido, los análisis con perspectiva de género son pertinentes para comprender cómo este complejo sociocultural le da identidad y pertenencia al sujeto dentro de una colectividad. Pero ello sin perder de vista las asimetrías de género que se tejen y que forman parte de la estructura social, pues se traducen en normas, reglas y prácticas a través de las cuales el sujeto encarna expresiones de la feminidad y la masculinidad.

\section{Diferencias de género en la educación musical}

Recurrir a la perspectiva de género para realizar nuestro análisis permitió visibilizar las inequidades que estuvieron presentes en los procesos de enseñanza musical. Por ejemplo, se hizo notar que la imagen femenina relacionada con la debilidad física representaba un problema, pues "era ver qué instrumentos de viento iban a ejecutar, cuál podía tocar una mujer, porque se requiere de mucha fuerza" (entrevista a fundadora, 2016). Por otro lado, el profesor de música de la Misión Cultural indicaba que por creencia común: "se recomienda a las mujeres que elijan instrumentos suaves de viento, como son las cañas, clarinetes, saxofón y saxofón soprano" (entrevista a profesor de la Misión Cultural, 2016). Es decir, la elección del instrumento no dependía de las habilidades del sujeto, sino de su fuerza. Para Goffman (2006), la 
debilidad física como una supuesta característica del individuo no es más que la estigmatización del sujeto, y esta funciona como un instrumento que produce discriminaciones y exclusiones. Es así como la debilidad física es vista como un atributo que desacredita la capacidad del sujeto para realizar ciertas actividades, como tocar un instrumento de viento.

En lo anterior se advierte que la enseñanza musical puede estar atravesada por el sexismo. Para Cabanes (2016), en su trabajo "Instrumentos musicales y género", las mujeres supuestamente eligen "instrumentos de chicas" como el flautín, la flauta y el clarinete, por ser pequeños y de menor peso. El estigma de la debilidad física fue un problema que enfrentó una de las informantes, quien tocó el trombón en la filarmónica:

\begin{abstract}
A los 14 años comencé a aprender solfeo [...] al elegir instrumento estaba indecisa [...] vi el trombón y me gustó el de vara más que el de émulos. Le comenté al maestro y me dijo que no porque yo era niña. "Tú ¿cómo vas a tocar el trombón? No vas a poder, es un instrumento para hombres. iPor qué no tocas clarinete o flauta o saxofón?, algo más chiquito" (entrevista a Griselda, 22 años, 2016).
\end{abstract}

El testimonio anterior ejemplifica lo que dice Valdebenito (2013), al señalar que los prejuicios de género pueden afectar la enseñanza y el aprendizaje musical debido a que se presentan restricciones relacionadas con estereotipos tradicionales de la feminidad. Este problema ha sido abordado por la musicología feminista y la musicología de género, desde cuyas perspectivas se considerar que la música ha sido constituida como un espacio masculino. Esto necesita ser problematizado de manera crítica para comprender cómo se gestan las construcciones de género en la enseñanza musical (Quintana, 2006; Ramos, 2003). De este modo, la perspectiva de género es una herramienta que enriquece el paradigma interpretativo para cuestionar las restricciones que enfrentan las mujeres cuando buscan participar en proyectos musicales, como fue el caso de la Filarmónica Juvenil San Martín Tilcajete.

\section{Empoderamiento: la función social de la música}

Parafraseando a Bertolt Brecht (en Tolokonnikova, 2018), la música puede no solo reflejar la realidad, sino ser un martillo para darle forma, es decir, puede despertar la capacidad de acción del sujeto para desafiar paradigmas que han sido interiorizados y establecidos como naturales. La iniciativa de la filarmónica se gestó con ese objetivo, como un acto creativo para potenciar las virtudes de las jóvenes y su agencia como sujetos, para abrir horizontes promisorios que impulsen su empoderamiento para re-equilibrar la balanza de poder entre individuos, grupos y géneros (Vázquez, Núñez y Ortega, 2018). En este sentido, empoderarse implica el desarrollo de capacidades para superar roles de género tradicionales. En el contexto indicado, la filarmónica fue un proyecto en el que, "al tener en cuenta el proceso histórico que crea la carencia de poder, se hace evidente la necesidad de alterar las estructuras sociales vigentes; es decir, de reconocer el imperativo del cambio" (León, 2001:97), ello a través de la educación musical.

Para una de las informantes participar en el proyecto significó "dar a conocer que las mujeres sí podemos, conocí gente, nuevos lugares, aprendí a leer partituras y a tocar un instrumento, no esperaba que la música me trajera esos resultados" (entrevista a Soledad, 22 años, 2015). Por su parte, una clarinetista explicó: "me gustan los aplausos y la admiración de la gente hacia mí, se siente bonito que te aplaudan cuando tocas" (entrevista a Norma, 17 años, 2016). Desarrollar una habilidad como tocar un instrumento y pertenecer a un proyecto como la Filarmónica Juvenil San Martín Tilcajete puede aumentar la autoestima individual y grupal, la cooperación y la solidaridad, elementos que son impulsores de empoderamiento (León, 2001; Vázquez, Núñez y Ortega, 2018).

Por ejemplo, para el fundador, "esa camada de chicas cambió muchísimo, empezaron a ser más independientes y responsables, conocieron el mundo y tuvieron un papel protagónico en la filarmónica, que consistía en elegir parte del repertorio" (entrevista, 2016). Lo antes citado puede representar una recomposición de la identidad que potencie su capacidad como actoras sociales 
y políticas, y que contribuya a resignificar y a reelaborar las relaciones de poder fuera de discursos hegemónicos del género. Para Pérez y Vázquez (2009), las actividades de este tipo ayudan a las mujeres a distanciarse del orden social que las subordina.

En esta dirección, aprender a ejecutar un instrumento musical puede verse como un logro, una apertura a la conquista de derechos y del espacio público. Por ejemplo, Griselda aprendió a tocar el trombón, participó en la filarmónica, luego en un ensamble de instrumentos de viento en la ciudad de Oaxaca, y formó parte de la banda femenil de Tlahuitoltepec. Ella explicó que recibir educación musical en la filarmónica le sirvió para incorporarse a dichos proyectos y viajar, "no me costó trabajo adaptarme porque ya sabía solfeo [...] nos presentamos en muchas regiones de Oaxaca, fuimos a Ciudad de México, Mérida y al Estado de México" (entrevista a Griselda, 22 años, 2016). De esta manera, la música es un canal de empoderamiento a partir del cual el sujeto experimenta una acción transformadora, le posibilita configurar otros paradigmas femeninos, porque empoderarse significa una mayor movilidad fuera y dentro de sus comunidades, una mayor autonomía al crear nuevas relaciones sociales (Lorey, 2017; Vázquez, Núñez y Ortega, 2018).

Sin embargo, a pesar de los intereses de la filarmónica como una iniciativa que representara un canal de empoderamiento para desafiar las jerarquías de género y otros mecanismos de subordinación (Rowlands, 1997), no estaban exentos de dificultades, debido a que la distribución desigual del poder entre mujeres y hombres está relacionada con el complejo sociocultural en el que habitan, lo que justifica las asimetrías de género al colocar la figura masculina como la dominante y la femenina como la subordinada. Según Vázquez, Núñez y Ortega (2018), el complejo sociocultural influye sobre la forma en que deben interactuar los habitantes de un espacio social; define los lugares que estos deben ocupar y las actividades propias de su sexo que deben realizar.

Los expuestos son factores inhibidores que afectan el proceso de empoderamiento de las mujeres. En relación con esto, para Hidalgo (2002) es pertinente considerar que en los procesos de empoderamiento existen conflictos, compensaciones y negociaciones que se presentan en todo momento, entendiendo al otro en su tiempo y espacio, sin dejar de lado categorías como edad, etnia y clase. Un ejemplo de lo anterior es el siguiente testimonio: "me costó trabajo convencer a mis papás [...] decían: 'son puros hombres, vas a viajar sola con ellos, qué va a pensar la gente de ti, qué van a decir'. Era otra vez la misma barrera del tradicionalismo" (entrevista a Griselda, 22 años, 2016). El conflicto, las compensaciones y las negociaciones son elementos para indicar que "el empoderamiento es un proceso heterogéneo, no acabado y que varía con el contexto" (Hidalgo, 2002:52). De este modo, documentar la experiencia de la filarmónica a través de sus protagonistas permitió realizar un análisis sobre la función social de la educación musical que, desde la perspectiva de género, ayudó a identificar la relación que tiene con los procesos de empoderamiento de las jóvenes. Y como advierten Urteaga y Sáenz:

\section{[...] el género como la juventud pueden ser vistos como nudos focales en los que se entrecruzan determinados contextos históricos particulares, que desde lo públi- co hasta lo íntimo, y desde lo global, hasta lo regional y lo local, acaban produciendo, vía el agente juvenil determinadas zonas fronterizas, espacios no transi- cionales, sino sitios de producción creativa, "porosos" por la heterogeneidad, movilidad y/o novedad de sus actores (Urteaga y Sáenz, 2012:6).}

En este orden de ideas, las reflexiones sobre juventudes rurales desde la perspectiva de género orientadas a los espacios de socialización, relacionados con el ocio, situaciones lúdicas y festivas, como fue el caso de la filarmónica, pueden abrir nuevas rutas de investigación. La juventud es un sujeto situado en un contexto de relaciones complejas, un actor social que cuenta con un agenciamiento y desempeña un papel central en la construcción del mundo contemporáneo (Bevilaqua, 2009; Urteaga, 2010). Parafraseando a Zemelman (1998), iniciativas como la de la Filarmónica Juvenil San Martín Tilcajete constituyen recursos que ayuden a recuperar la potencia del sujeto como histórico para 
abrirse a la realidad, a través de una dialéctica de instalación-apropiación de la realidad-mundo, y así superar el bloqueo que impone el poder patriarcal.

\section{Conclusiones}

Este artículo tiene como objetivo analizar desde la perspectiva de género las experiencias de las jóvenes que participaron en el proyecto de la Filarmónica Juvenil San Martín Tilcajete, bajo la cual se les considera como sujetos situados que construyen su identidad de género en circunstancias complejas y heterogéneas. Elegir este proyecto como unidad de análisis tuvo una doble intención. La primera consistió en documentar la experiencia de esta iniciativa como evidencia de la función social que tiene la música y su enseñanza como impulsoras de la agencia del sujeto joven, para así concluir que proyectos de promoción y difusión cultural como espacios alternativos para la transformación social de las comunidades rurales requieren del apoyo de autoridades culturales locales, estatales y federales, y así conseguir que se consoliden.

La segunda intención consistió en realizar una reflexión sobre juventudes rurales como actores sociales que producen cultura juvenil desde sus espacios de socialización, como el tiempo de ocio, los contextos lúdicos y las actividades festivas. En consecuencia, iniciativas como la filarmónica no solo pueden representar un espacio de inclusión para la juventud, que potencia el desarrollo individual y comunitario, sino posibilitar además la conquista del espacio público por parte de las mujeres en sus comunidades. Este proyecto pretendió ser un canal para potenciar el empoderamiento de las jóvenes, lo que implicó un desafío a la estructura patriarcal que predomina en la comunidad y que perpetúa las desigualdades de género e inhibe el empoderamiento.

Fortalecer aspectos como la autoestima individualy colectiva a través de la educación musical permite favorecer la recomposición de la identidad femenina y, por ende, influir en las representaciones sociales del género. Sin embargo, el proceso de empoderamiento está lleno de dificultades. En el análisis de las entrevistas, las jóvenes evidenciaron que, a pesar de los cambios culturales, laborales y familiares en la comunidad, seguía imperando la desigualdad y exclusión por razones de género. Imperaba una violencia simbólica que estaba presente en el sistema sociocultural - usos y costumbres- de la comunidad y que reforzaba estereotipos hegemónicos y reduccionistas de género. En consecuencia, esto proyectaba una actitud que desvalorizaba la capacidad de agencia de las mujeres jóvenes, al considerarlas como sujetos con cuerpos vulnerables, resultado de una mala distribución del poder. Esto dificultó que se pudieran integrar fácilmente al proyecto y, al hacerlo, estos problemas se presentaron en la docencia musical, lo que contrastaba con el objetivo de hacer de la educación musical un recurso promotor de la equidad de género.

Las jóvenes eran estigmatizadas, pues la debilidad física como supuesta característica femenina influyó al momento de elegir el instrumento musical, ya que debían optar por uno pequeño y ligero, es decir, de "mujeres". En este sentido, al analizar los procesos de empoderamiento desde los parámetros de cada sociedad relacionados con lo etario y con la etnia, es pertinente dar cuenta de los conflictos, las compensaciones y las negociaciones que se presentan. Estos parámetros están relacionados con el apoyo de personas cercanas, principalmente de la familia, que son factores impulsores o inhibidores del proceso, ya que uno de los niveles de empoderamiento, como lo es el de las relaciones cercanas, es más difícil de cambiar (Pérez y Vázquez, 2009). Esto permitió exponer las situaciones complejas que enfrentaron las jóvenes para participar en la filarmónica.

Para finalizar, ratificamos que el género, como categoría de análisis, resultó primordial para conocer que iniciativas como la Filarmónica Juvenil San Martín Tilcajete pueden potenciar el empoderamiento de las jóvenes rurales, porque influyen en las trayectorias individuales, en los proyectos de vida y en los procesos de construcción subjetiva e identitaria, para que adquieran poco a poco conciencia de sus derechos y libertades, ello sin dejar de lado que la juventud rural es un sujeto situado ligado a la construcción social del género de su comunidad. Las reflexiones que presentamos expresan la necesidad de dejar atrás la mirada ingenua, paternalista, adultocéntrica y androcéntrica 
sobre las juventudes rurales, para indicar que son un grupo heterogéneo con distintas necesidades políticas, económicas y sociales. Si bien se propuso contemplar a la juventud rural y sus interconexiones con el género, la etnia y los espacios de socialización, desde un proyecto como el de la filarmónica, es necesario advertir que esto puede tener ciertas limitaciones que necesitarán ampliarse en futuras investigaciones.

\section{Notas}

${ }^{1}$ Este artículo se basa en la investigación de tesis de maestría en Estudios del Desarrollo Rural realizada por las y los autores con la financiación del Consejo Nacional de Ciencia y Tecnología (CONACYT), así como del Colegio de Postgraduados en Ciencias Agrícolas, México.

2 Por motivos de confidencialidad, los nombres de las informantes fueron cambiados por otros ficticios para proteger su identidad.

3 Saraví conceptualiza la fragmentación social como "un distanciamiento sociocultural asociado a la desigualdad socioeconómica o de clase" (2015: 29). También habría que agregar el género y la etnia como categorías que intervienen en las exclusiones reciprocas e inclusiones desiguales.

\section{Referencias}

Aristóteles (2005). Política. Madrid: Istmo.

Alberti Manzanares, Pilar (2011). "Los estudios de género y su crítica al androcentrismo en las Ciencias Sociales". En María J. Rodríguez-Shadow y Lilia Campos (eds.), Mujeres: miradas interdisciplinarias. México: Centro de Estudios de Antropología de la Mujer, pp. 213-235.

Alvarado Juárez, Ana Margarita. (2008). “Migración y pobreza en Oaxaca”. En El Cotidiano, 23(148), marzoabril, 85-94.

Bailón Corres, Moisés, Carlos Sorroza Polo y Todd Eisenstadt (2016). Democracia, derechos humanos y derechos indígenas en municipios de usos y costumbres: resultados de una encuesta. México: Instituto Estatal Electoral y de Participación Ciudadana.
Bevilaqua Marin, Joel Orlando (2009). "Juventud rural: una invención del capitalismo industrial”. En Estudios Sociológicos, 80, mayo-agosto, 619-653.

Bourdieu, Pierre y Jean-Claude Passeron (1996). La reproducción. Elementos para una teoría del sistema de enseñanza. México: Laia.

Buendía Silva, Daniela (2013). Desarrollo Rural Exploraciones 18. Mujeres jóvenes rurales en Colombia. La Paz: Instituto para el Desarrollo Rural de Sudamérica.

Burin, Mabel (2012). "Género y salud mental: construcción de la subjetividad femenina y masculina". Disponible en http://dspace.uces.edu.ar:8180/xmlui/bitstream/handle/123456789/1529/Burin_2010_Preprint.pdf?sequence=1 (consultado 31 de agosto de 2019).

Butler, Judith (2017). "Vulnerabilidad corporal, coalición y la política de la calle”. En Nómadas, 46, abril, 13-29.

Cabanes Sempere, Aranzazu (2016). "Instrumentos musicales y género". Disponible en http://www.cimapolo.com/gral/contrib/Instrumentos-y-genero.html (consultado el 22 de agosto de 2019).

Colectivo Hombres y Masculinidades (2009). De machos a hombres: violencia de género y desplazamiento forzado. Bogotá: Alto Comisionado de las Naciones Unidas para los Refugiados.

CONEVAL (Consejo Nacional de Evaluación de la Política de Desarrollo Social) (2018). Estudio diagnóstico del derecho a la educación 2018. México: CONEVAL.

De Garay, Adrián (2000). "El consumo cultural de los jóvenes universitarios en la Ciudad de México: una realidad ignorada". En Eli Martínez y Alejandra León Ibarra (comp.), La juventud en la Ciudad de México: politicas, programas, retos y perspectivas. México: Gobierno del Distrito Federal, pp. 109-122.

De la Ossa, Marco (2011). "La sociología de la música: relación con la ed. musical en la etapa de ed. primaria". En Música y Educación, 24(87), 18-35.

DIGEPO (Dirección General de Población de Oaxaca) (s/f). Radiografía sobre migración internacional: México y Oaxaca. México: DIGEPO.

Duarte Quapper, Klaudio (2001) “iJuventud o juventudes?". En Solum Donas Burak (comp.), Adolescencia y juventud en América Latina. San José, Costa Rica: Libro Universitario Regional, pp. 57-74. 
Esparza Bautista, José (2016). Políticas culturales comunitarias: una metanarrativa de la política cultural municipal a partir de tres experiencias relevantes de promoción cultural comunitaria en el sur-sureste de México 2013-2015. Tesis de doctorado. México: BUAP.

Flores Mercado, Georgina (2011). “Antes se tocaba papel, se estudiaba con un maestro. Remembranzas de la educación musical rural en Totolapan, Morelos”. En Alteridades, 21(42), julio-diciembre, 149-163.

García Suárez, Carlos Iván y José Fernando Serrano Amaya (2004). "Género y juventud en los procesos de subjetivación”. En María Cristina Laverde Toscano, Gisela Daza Navarrete y Mónica Zuleta Pardo (dir.), Debates sobre el sujeto: perspectivas contemporáneas. Bogotá: Siglo del Hombre Editores.

Giménez, Gilberto (2016). Estudios sobre la cultura y las identidades sociales. Guadalajara: Universidad de Guadalajara.

Goffman, Erving (2006). Estigma. La identidad deteriorada. Buenos Aires: Amorrortu.

Hernández Estrada, José (2014). "Las orquestas infantiles y juveniles de México inspiradas por el sistema. Legado, evolución y desafíos". Disponible en https://www. joseherstrada.com/blog/blog/las-orquestas-infantiles-yjuveniles-de-mexico-inspiradas-por-el-sistema-legadoevolucion-y-desafios (consultado el 16 de agosto de 2019).

Hidalgo Celarié, Nidia (2002). Género, empoderamiento y microfinanzas. Un estudio de caso en el norte de México. Tesis de maestría. México: Instituto Nacional de las Mujeres.

Hormigos Ruiz, Jaime (2012). “La sociología de la música. Teorías clásicas y puntos de partida en la definición de la disciplina". En Barataria, 14, 75-84.

Jiménez Guzmán, María Lucero y Serena Serrano Oswald (2014). "Identidades de género, machismo y masculinidades en San Martín Tilcajete, Oaxaca: reflexiones en torno a la justicia social a partir de un estudio de caso". En GénEros, 14, 57-77.

Lorey, Isabell (2017). Disputas sobre el sujeto. Consecuencias teóricas y políticas de un modelo de poder jurídico: Judith Butler. Buenos Aires: La Cebra.

León, Magdalena (2001). "El empoderamiento de las mujeres: Encuentro del primer y tercer mundos en los estudios de género". En La Ventana, 13, 94-106.
Margulis, Mario y Marcelo Urresti (2002). "La construcción social de la condición de juventud”. En Humberto Cubides, María Laverde, Carlos Valderrama y Mario Margulis (eds.), "Viviendo a toda”. Jóvenes, territorios culturales y nuevas sensibilidades. Bogotá: Siglo del Hombre Editores, pp. 2-21.

Margulis, Mario (2001). "Juventud una aproximación conceptual”. En Solum Donas (comp.), Adolescencia y juventud en América Latina. San José, Costa Rica: Libro Universitario Regional, pp. 41-56.

Paz Calderón, Yannet, María Suárez Zozaya y Mónica Espinosa Espíndola (2018). "La construcción histórica del sujeto joven en México”. En LiminaR. Estudios Sociales y Humanísticos, 16(1), enero-junio, 13-24.

Pérez Villar, María de los Ángeles y Verónica Vázquez García (2009). "Familia y empoderamiento femenino: ingresos, trabajo doméstico y libertad de movimiento de mujeres chontales de Nacajuca, Tabasco". En Ciencias Sociales, 50, mayo-agosto, 187-218.

Quintana Martínez, Alejandra (2006). Género, poder y tradición. Al baile de la gaita al caimán le repica. Estudio de la música de gaitas y tambores de la Costa Atlántica colombiana (San Jacinto, Ovejas y Bogotâ) desde una perspectiva de género. Tesis de maestría. Colombia: Universidad Nacional de Colombia.

Ramos López, Pilar (2003). Feminismo y música. Introducción crítica. Madrid: Narcea.

Reguillo, Rossana (2007). Emergencia de culturas juveniles. Estrategias del desencanto. Bogotá: Grupo Editorial Norma.

Reynoso Vargas, Karla María (2010). "La educación musical y su impacto en el desarrollo". En Educación y De sarrollo, 12, enero-marzo, 53-60.

Rosas Vargas, Rocío y Emma Zapata Martelo (2007). "Introducción". En Rocío Rosas Vargas y Emma Zapata Martelo (coords.), Mujeres en la bruma. Tenencia de la tierra en Guanajuato. México: Colegio de Postgraduados en Ciencias Agrícolas, pp. 1-45.

Rowlands, Jo (1997). "Empoderamiento y mujeres rurales en Honduras: Un modelo para el desarrollo". En Magdalena León (comp.), Poder y empoderamiento de las mujeres. Bogotá: Tercer Mundo, pp. 213-245.

Sandoval Casilimas, Carlos (2002). Investigación cualitativa. Bogotá: ARFO. 
Santana Echeagaray, María Eugenia, Edith Kauffer y Emma Zapata Martelo (2006). "El empoderamiento de las mujeres desde una lectura feminista de la Biblia: el caso de la CODIMUJ en Chiapas". En Convergencia, 13(40), enero-abril, 69-106.

Saraví, Gonzalo (2015). Juventudes fragmentadas. Socialización, clase y cultura en la construcción de la desigualdad. México: FLACSO/CIESAS.

Sili, Marcelo, Sandra Fachelli y Andrés Meiller (2016). "Juventud rural: factores que influyen en el desarrollo de la actividad agropecuaria. Reflexiones sobre el caso argentino". En Revista de Economia e Sociología Rural, Piracicaba, 54(4), octubre-diciembre, 635-652.

Sosa, Yadira (2019). "Aumentan en 33\% los feminicidios en Oaxaca”. En El Imparcial, 19 de mayo.

Taylor, Steven y Robert Bogdan (1994). Introducción a los métodos cualitativos de investigación. La búsqueda de significados. Barcelona: Paidós.

Tolokonnikova, Nadya (2018). Pussy Riot. De la alegría subversiva a la acción directa. Barcelona: Roca Editorial.

Urteaga Castro-Pozo, Maritza (2010). "Género, clase y etnia. Los modos de ser joven". En Rossana Reguillo (comp.), Los jóvenes en México. México: FCE, CONACULTA, pp. 15-51.

Urteaga Castro-Pozo, Maritza (2019). "Adolescencia y juventud: reposicionamientos teóricos". En Investigaciones Ssociales, 22(40), 59-72.

Urteaga Castro-Pozo, Maritza y Mauricio Sáenz Ramírez (2012). "Juventudes, género y sexos". En Revista del Centro de Investigación, 10(37), enero-junio, 5-21.
Valdebenito Carrasco, Lorena (2013). "Educación musical y género: una perspectiva inclusiva desde el currículum de aula”. En Neuma, 6(2), 58-66.

Vargas García, Itzel (2016). "El potencial de la música en las prácticas (re)vitalizadoras y de fortalecimiento lingüístico y cultural de los pueblos indígenas mexicanos". En Cuicuilco, 66, mayo-agosto, 75-93.

Vázquez García, Verónica, Naima Cárcamo Toalá y Neftalí Hernández Martínez (2011). Usos y costumbres y ciudadanía femenina. Hablan las presidentas municipales de Oaxaca, 1996-2010. México: Miguel Ángel Porrúa, Colegio de Postgraduados en Ciencias Agrícolas.

Vázquez García, Verónica y Carolina Muñoz Rodríguez (2013). "Género, etnia y participación política en San Pedro y San Pablo Ayutla, Oaxaca. Una primera aproximación”. En Región y Sociedad, 25(57), mayo-agosto, 137-163.

Vázquez García, Verónica, Juan Núñez Espinoza y Tomás Ortega Ortega (2018). “Estructura y resiliencia social en comunidades indígenas: el caso de la Unión de Palmeadoras de Tlaxiaco, Oaxaca, México". En REDES, 29 (2), 206-225.

Wald, Gabriela (2017). "Orquestas juveniles con fines de inclusión social. De identidades, subjetividades y transformación social". En Foro de Educación Musical, Artes y Pedagogía, 2(2), marzo, 59-81.

Zemelman, Hugo (1998). Sujeto: existencia y potencia. México: Anthropos.

Zemelman, Hugo (2012). Pensar y poder. Razonary gramática del pensar histórico. México: Siglo XXI. 